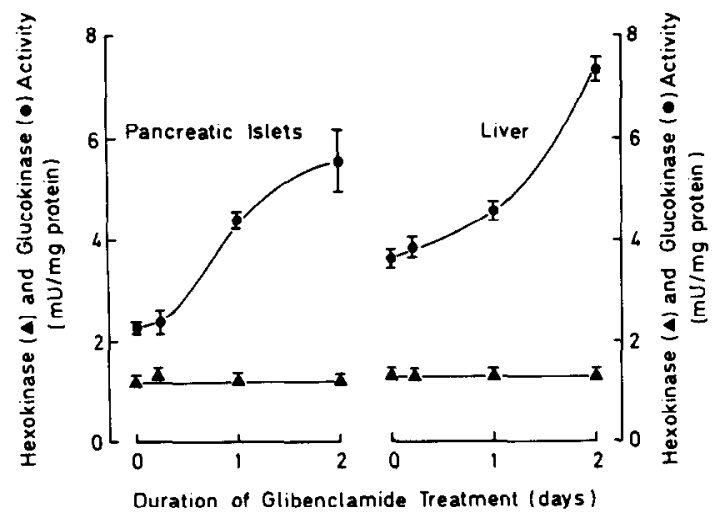

Fig. 3. Time-dependent induction $(P<0.05$; Anova $)$ of pancreatic islet and liver glucokinase $(O)(\mathrm{mU} / \mathrm{mg}$ protein) by glibenclamide treatment (once 4 hours, twice daily for 1 day and twice daily for 2 days $0.4 \mathrm{mg} / \mathrm{kg}$ body weight s.c. before measurement) in four-day starved rats. Pancreatic islet and liver hexokinase $(\boldsymbol{\Delta})(\mathrm{mU} / \mathrm{mg}$ protein) were not affected by glibenclamide treatment. Values shown are the means \pm S.E. for $3-18$ experiments.

Hexokinase activities from both tissues were slightly reduced by fasting (Fig. 1) but not affected by glibenclamide treatment in any of the experiments (Figs 1-3).

The inductive effect of glibenclamide treatment on glucokinase is not a direct effect of glibenclamide but rather an effect of the insulin released from the pancreatic B-cells in response to glibenclamide stimulation. This is proven by the fact that fed rats made diabetic (serum glucose concentrations above $15 \mathrm{mM}$ ) by injection of alloxan $(100 \mathrm{mg} /$ $\mathrm{kg} \mathrm{b}$. wt. four days before the experiment) presented liver glucokinase activities in the range of those observed in the liver from fasted non-diabetic rats [14] $(4.7 \pm 0.4 \mathrm{mU} / \mathrm{mg}$ protein; $\mathrm{N}=3$ ). These low liver glucokinase activities from diabetic rats were not significantly raised by glibenclamide treatment $(6.1 \pm 0.1 \mathrm{mU} / \mathrm{mg}$ protein $\mathrm{N}=4)$ but normalized by insulin treatment $(12.4 \pm 1.3 \mathrm{mU} / \mathrm{mg}$ protein; $\mathbf{N}=6$ ).

Thus our experiments have shown that hypoglycemic sulfonylureas such as glibenclamide can maintain their longterm hypoglycemic action through induction of pancreatic islet and liver glucokinase by insulin. Induction of pancreatic islet glucokinase keeps the glucose recognition system sensitive for the initiation of insulin secretion and biosynthesis by glucose stimulation. This induction of pancreatic islet glucokinase by insulin augments the signal generating flux rate through the glycolytic pathway relative to the actual glucose concentration surrounding the pancreatic B-cell. A sustained insulin secretory response of the pancreatic B-cell to absorptive and post-absorptive glucose keeps liver glucokinase in an induced state. This enables the liver to regulate the blood glucose concentration. Thus the induction of glucokinase in vivo represents a link between the pancreatic and extrapancreatic effects of glibenclamide and provides an explanation for the interaction between pancreatic islets and liver in the maintenance of glucose homeostasis [15].

Acknowledgements-S.L. is greatly indebted to Professor D. G. Walker, Dept. of Biochemistry, University of Birmingham, for providing glucokinase antibody. This investigation was supported by the Deutsche Forschungsgemeinschaft.

Institute of Pharmacology and

Toxicology

University of Göttingen

Robert-Koch-Str. 40

D-3400 Göttingen

Federal Republic of Germany

SiguRd LeNZEN

MARKUS TIEDGE

UWE PANTEN

\section{REFERENCES}

1. B. Hellman and I.-B. Täljedal, in Handbook of Experimental Pharmacology (Eds. A. Hasselblatt and F. von Bruchhausen, p. 175 Springer-Verlag, Berlin (1975).

2. S. Lenzen, FEBS Lett. 49, 407 (1975)

3. D. G. Walker, Essays Biochem. 2, 33 (1966).

4. H. Niemcyer, T. Ureta and L. Clark-Tarri, Mol. Cell. Biochem. 6, 109 (1976).

5. S. Weinhouse, Curr. Top. Cell. Reg. 11, 1 (1976).

6. M. D. Meglasson and F. M. Matschinsky, Am. J. Physiol 246, E1 (1984).

7. A. C. Storer and A. Cornish-Bowden, Biochem. J. 159 7 (1976).

8. S. Lenzen and U. Panten, Analyt. Biochem. 149, 301 (1985).

9. S. Lenzen, W. Schmidt and U. Panten, J. biol. Chem. 260, 12629 (1985)

10. D. G. Walker and M. J. Parry, Methods Enzymol. 9, 381 (1966).

11. S. H. Grossman, C. G. Dorn and R. van Potter, $J$. biol. Chem. 249, 3055 (1974).

12. W. Sibrowski and H. J. Seitz, Eur. J. Biochem. 113, 121 (1980)

13. G. M. Lawrence, D. G. Walker and J. P. Trayer, Biochim. biophys. Acta 743, 219 (1983).

14. D. G. Walker and S. Rao, Biochem. J. 90, 360 (1964).

15. J. B. Halter, W. K. Ward, D. Porte, J. D. Best and M. A. Pfeiffer, Am. J. Med. 79 (suppl 2B), 6 (1985).

\title{
Uptake and accumulation of gentamicin in the developing inner ear of the mouse in vitro
}

(Received 18 November 1985; accepted 24 January 1986)

The sequences of both the bactericidal and the nephrotoxic actions of the aminoglycoside antibiotics include an energydependent uptake into the affected cells [1-3]. Whether an analogous step is also part of the ototoxic mechanism is not known. Pharmacokinetic studies relating to the cochlear actions of the aminoglycosides have only provided information on drug disposition in the fluids $[4,5]$ and the tissues of the inner ear $[6,7]$. Questions of transport mechanisms or related issues such as whether the aminoglycosides enter the cells passively along, or actively against, a concentration gradient have not been addressed yet. Electrophysiological studies, however, have suggested that the ototoxic actions of gentamicin require an as yet undefined energy-dependent process [8], and a cellular uptake was postulated in a recent model of aminoglycoside ototoxicity [9].

To determine parameters of uptake, the drug con- 
centrations in both the surrounding fluid and the tissue have to be known. Two problems arise with the inner ear. First, measurements of tissue volume (via wet weight) are difficult to obtain. Because of the small amount and the high surface to volume ratio of the tissues, adhering endolymphatic or perilymphatic fluid can produce large errors in the estimate of wet weight. Second, pharmacokinetic studies have so far been unable to determine whether serum, perilymph or endolymph, is the preferred route of drug access to the labyrinthine tissues.

The present study minimizes these complications by measuring the uptake of gentamicin into the inner ear in organ culture. The embryonic inner ear is easy to manipulate, will differentiate in culture [10], and is susceptible to aminoglycosides [11]. Drug concentrations in the culture medium can be defined and compared to those in the otic explants.

\section{Materials and methods}

Organ culture. Normal hybrid CBA/C57 mouse embryos were obtained by mating CBA-J and C57 mice (Jackson Laboratories, Bar Harbor, ME). The day at which a mucoid vaginal plug was found was designated as the first day of gestation. On gestational day 16 , pregnant mice were killed by cervical dislocation, and their gravid uteri were placed in Dulbecco's phosphate-buffered saline (PBS). Embryos were removed, and their developmental stages were assessed [12]. The embryonic inner ear with its associated cartilaginous otic capsule and ganglionic tissue was dissected and explanted to organ culture dishes. Care was taken to free the otic explants of any adhering middle ear mesenchyme.

Each culture dish (Falcon, $35 \times 10 \mathrm{~mm}$; Becton, Dickinson \& Co., Oxnard, CA) contained three otic explants in $2 \mathrm{ml}$ of Neumann-Tytell medium (Gibco Laboratories, Grand Island, NY), supplemented with $20 \%$ fetal calf serum and $25 \mu \mathrm{g}$ ascorbic acid $/ \mathrm{ml}$. Explants were grown under $5 \% \mathrm{CO}_{2}$ in air (95\% relative humidity) at $36.5^{\circ}$ for 1,3 or 5 days. When indicated, gentamicin was added at concentrations of 0.1 to approximately $20 \mu \mathrm{g} / \mathrm{ml}$ culture medium. At the end of the culture period, explants were washed twice in PBS, blotted on filter paper, weighed, and pooled in sterile plastic tubes. Samples of culture medium were also withdrawn from each dish. Explants and medium were stored at $-20^{\circ}$ until assayed for their aminoglycoside levels.

Assays. The otocysts were homogenized in $0.2 \mathrm{M}$ potassium phosphate, $\mathrm{pH} 8.0$, and protein was measured in the homogenates [13]. Gentamicin was determined in the supernatant fraction after centrifugation at $12,000 \mathrm{~g}$ for $10 \mathrm{~min}$ [7]. The radioimmunoassay (American Bioclinical, Portland, OR) was modified after Meulemans et al. [14] to increase sensitivity.

\section{Results and discussion}

Otic explants developed in organ culture without any gross pathology induced by gentamicin. The average gain in weight and protein content of the explants during culture was not affected significantly by the presence of the drug ( $13.5 \mu \mathrm{g}$ increase in protein/explant from day 1 to day 5 for controls vs $12.7 \mu \mathrm{g}$ at $10 \mu \mathrm{g}$ gentamicin/ml of medium). Morphogenesis appeared normal with well-defined semicircular ducts and a coiled cochlear duct (Fig. 1). It should be noted, however, that pathological changes in hair cells have been observed by transmission electron microscopy in explants cultured at gentamicin concentrations of $1 \mu \mathrm{g} /$ $\mathrm{ml}$ or greater [11], indicating that the developing inner ear is susceptible to damage by aminoglycosides.

The uptake of gentamicin into the inncr ear was dependent on both time and drug concentration in the medium (Fig. 2). Incubations without gentamicin served as controls for the specificity of the drug assay. It is interesting to note that the concentrations in the explants $(0.1$ to $1 \mu \mathrm{g}$

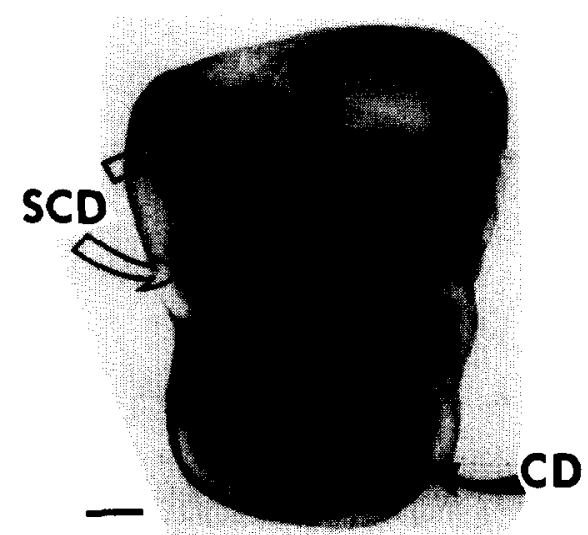

Fig. 1. Otic explant of 16-day-old embryo after 5 days in vitro. The explant was grown in the presence of $10 \mu \mathrm{g}$ gentamicin $/ \mathrm{ml}$ of culture medium as described in Materials and Methods. Morphogenesis is normal with well-defined semicircular ducts (SCD) and a coiled cochlear duct (CD). Calibration bar $=100 \mu \mathrm{m}$.

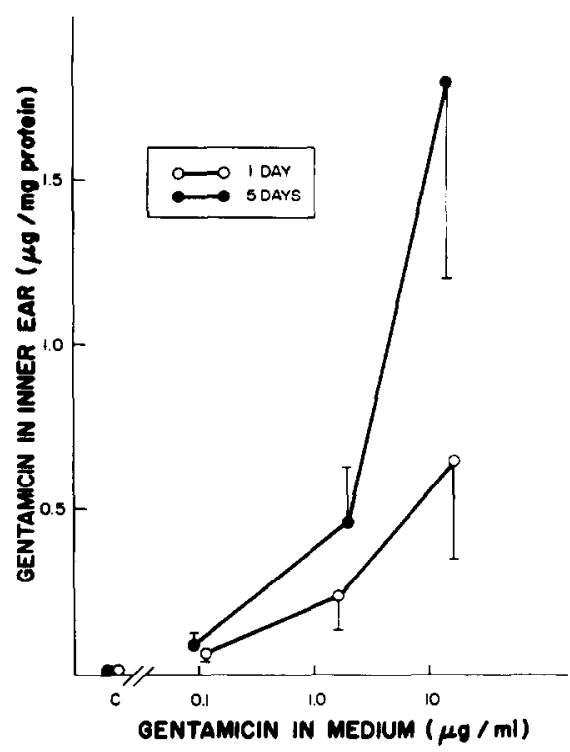

Fig. 2. Concentration- and time-dependency of gentamicin uptake. Otic explants were cultured for $1\left(\mathrm{O}^{\circ}\right)$ or 5 (-) days at different gentamicin concentrations in the medium as described in Materials and Methods. Values are means $\pm S$.D. from three otocysts per condition, each analyzed in duplicate. Note that the gentamicin concentration on the abscissa is displayed in logarithmic units.

"C", control incubation without gentamicin.

gentamicin/mg protein) were comparable to those reported for neomycin and gentamicin in inner ear tissues of the adult guinea pig and the rat after in vivo treatment with aminoglycosides $[6,7]$.

The significant finding of this study is the observation that otic explants accumulated gentamicin over concentrations in the culture medium. Concentrations of gentamicin in the inner ear were determined assuming that $1 \mathrm{mg}$ (wet weight) of tissue is equivalent to $1 \mu \mathrm{l}$ of volume. Over the range of 0.1 to $17 \mu \mathrm{g} \mathrm{drug} / \mathrm{ml}$ of medium, the ratios of concentrations in the explants to those in the medium were inversely proportional to the drug concentration. Genta- 
Table 1. Accumulation of gentamicin in the inner ear

\begin{tabular}{cccc}
\hline $\begin{array}{c}\text { Incubation } \\
\text { time } \\
\text { (days) }\end{array}$ & \multicolumn{3}{c}{ Gentamicin concentration } \\
& \multicolumn{2}{c}{$\begin{array}{c}\text { Medium }{ }^{*}(\mu \mathrm{g} / \mathrm{ml}) \\
\text { Explant }\end{array}$} & Ratio ${ }^{+}$ \\
\hline 1 & 0.12 & 1.10 & \\
1 & 1.6 & 3.8 & 9.2 \\
1 & 17.0 & 11.6 & 0.7 \\
3 & 0.19 & 2.11 & 11.1 \\
5 & 0.09 & 1.50 & 16.7 \\
5 & 0.19 & 2.57 & 13.5 \\
5 & 2.1 & 8.5 & 4.0 \\
5 & 13.7 & 38.6 & 2.8 \\
\hline
\end{tabular}

Otic explants were cultured in two sets of independent experiments and analyzed as described in Materials and Methods. Both sets of experiments were incorporated into this table. In the first set, three explants were incubated per condition; in the second set, six explants each were incubated for 3 and 5 days at $0.19 \mu \mathrm{g}$ gentamicin $/ \mathrm{ml}$ medium. Otic explants were analyzed individually for their gentamicin and protein content (see Fig. 1 for gentamicin concentrations $/ \mathrm{mg}$ protein and standard deviations of the first set). For the weight determination, the three otic explants that were cultured together per dish were weighed together at the end of the incubation. To obtain gentamicin concentrations $/ \mathrm{mg}$ explant, total gentamicin for these explants was calculated and divided by their combined weight.

* Concentration at the end of the culture period. There were no significant differences in drug concentrations between the beginning and the end of the incubation. Numbers are means of at least duplicate determinations (each within $10 \%$ of the mean).

+ Ratio of gentamicin concentrations in otic explants to those in the culture medium.

micin concentrations were up to 16 -fold higher in the otic explants (Table 1).

The results clearly indicate that the uptake of gentamicin into the inner ear proceeds against a concentration gradient, suggesting an active (i.e. energy-dependent) transport. Although its characteristics have yet to be elucidated, the gentamicin uptake appears to obey Michaelis-Menten kinetics. The 5-day time points (Lineweaver-Burk analysis, correlation coefficient, $r^{2}=0.98$ ) yielded a $K_{m}$ of $1.9 \mu \mathrm{M}$. In remarkably good agreement, $K_{m}$ calculated from the 1day time points $\left(r^{2}=0.98\right)$ was $1.5 \mu \mathrm{M}$. The presence of a high-affinity uptake system for gentamicin in inner ear tissues has important implications for an understanding of the ototoxic actions of aminoglycoside antibiotics.

In summary, the developing inner ear in culture took up gentamicin from the surrounding medium against a

* To whom correspondence should be addressed. concentration gradient with an apparent $K_{m}$ of approximately $1.7 \mu \mathrm{M}$. Inner ears of $\mathrm{CBA} / \mathrm{C} 57$ hybrid mouse embryos were explanted at gestational day 16 and maintained in organ culture for 1,3 or 5 days in media containing from 0 to $17 \mu \mathrm{g}$ gentamicin $/ \mathrm{ml}$. Gentamicin concentrations in the otocysts increased with incubation time and exceeded the drug concentration in the medium up to 16 -fold. This is the first suggestion that tissues of the inner ear may actively transport aminoglycoside antibiotics by a highaffinity uptake system.

Acknowledgements-The authors are indebted to Laila Mahran and Mary Harrington for excellent assistance. This work was supported by Research Grant NS-13792 and NS08365 from the National Institutes of Health.

Kresge Hearing Research Institute

JOCHEN SCHACHT*

The University of Michigan

Ann Arbor, MI 48109, U.S.A.

Laboratory of Developmental THOMAS VAN DE WATER Otobiology

Department of Otolaryngology and

Neuroscience

Albert Einstein College of Medicine

Bronx, NY 10461, U.S.A.

\section{REFERENCES}

1. R. E. W. Hancock, J. Antimicrob. Chemother. 8, 249 (1981).

2. W. M. Kluwe and J. B. Hook, Toxic. appl. Pharmac. 45, 531 (1978).

3. P. Pastoriza-Munoz, R. L. Bowman and G. L. Kaloyanides, Kidney Int. 16, 440 (1979).

4. H. F. Stupp, Acta oto-lar. Suppl. 262, 8 (1970).

5. P. Tran Ba Huy, C. Manuel, A. Meulemans, O. Sterkers and C. Amiel, J. infect. Dis. 143, 476 (1981).

6. C. S. Desrochers and J. Schacht, Acta oto-lar. 93, 233 (1982).

7. P. Tran Ba Huy, P. Bernard and J. Schacht, J. clin. Invest., in press.

8. ^. Takada, S. Bledsoe and J. Schacht, Hearing Res. 19, 245 (1985)

9. J. Schacht, Hearing Res., in press.

10. T. Van De Water and R. J. Ruben, Ann. Otol. Rhinol. Lar. 83 (Suppl. 14), 1 (1974).

11. M. Anniko, A. Takada and J. Schacht, Am. J. Otolar. 3, 422 (1982).

12. K. Theiler, The House Mouse: Development and Normal Stages from Fertilization to Four Weeks of Age. Springer, Berlin (1972)

13. O. H. Lowry, N. J. Rosebrough, A. L. Farr and R. J. Randall, J, biol. Chem. 193, 265 (1951).

14. A. Meulemans, C. Manuel and P. Tran Ba Huy, Chemotherapy 27, 29 (1981).

\section{Ketoconazole hepatotoxicity: an in vitro model}

(Received 7 February 1985; accepted 24 January 1986)

Ketoconazole is the newest in a series of imidazole-derivative antifungal agents. It has a broad spectrum of activity against both superficial and systemic mycoses [1-3]. Ketoconazole is distinct from other antifungal imidazoles in clinical use. It is the only one that is absorbed in sufficient quantity to achieve therapeutic blood levels. Thus, it is effective when given orally $[2,4]$. It does not induce its own metabolism in vivo, nor that of other drugs in vitro [5].
Like other imidazoles, however, it inhibits the metabolism of some drugs in clinical situations [6,7]; recent reports have suggested that it does so by inhibiting the microsomal P-450 enzyme system [8].

As clinical use of ketoconazole increased, reports of adverse hepatic reactions appeared [9-11]. There are two general categories of reactions. Asymptomatic elevations of hepatocellular enzymes occur in $5-10 \%$ of patients at 